\title{
KADAR DEBU DAN KELUHAN PERNAFASAN TENAGA KERJA (Studi Kasus Pada Tenaga Kerja di Gudang dan Penyortiran Bahan Baku Produksi Tali Rfia PT. Hobab Perkasa di Jombang)
}

\author{
Anjar Pra Setyaningati, Musta'in, Erna Triastuti
}

\begin{abstract}
Impacts of dust exposure may disturb working enjoymeny and in longer priod may cause disturbances on respiratory passages and pulmonary functions. In addition to dust exposure, respiratory complaints may be caused by other factors relating to the workers, such as age, length of occupation that may explain how long was a worker was exposed to dust, smoking habit and their habit in wearing protective masks to protect their respiration. The purposes of this research was to describe level of dust concentration and complaints relating to workers' respiration. The study also engaged in the assessment of controlling efforts that include technical, administrative controls and the use self-protective devices

This was a descriptive study using a cross sectional approach. Data collection was done by observation, interviews and measurements. Population under study was the entire workers who worked at warehouses and raw material sorting division. The number of the sample was the total of population of workers that amounted to 30 workers. Data were analyzed descriptively using cross tabulation which explained the object under study.

Result of the study indicated that the dust level measured from 30 samples was in compliance to the TLV (57\%) that was $0.15 \mathrm{mg} / \mathrm{m}^{3}$. Most of workers $(63 \%)$ aged $\leq 40$ years old. Most of workers (63\%) have smoking habit. Most of worker $(93 \%)$ did not wear masks while working. Most of the workers $(60 \%)$ have moderate complaint. The efforts in controlling the issue was not satisfactory. Respiration complaints more likely associated to length of occupation, smoking habit, and utilization of protective masks.

The study suggested to install Local Exhaust Ventilation to reduce dust level in the workplace; the company was encouraged to make cooperation with related institutions in conducting $\mathrm{OSH}$ or $\mathrm{K} 3$ training, and the company should give rigid penalties against workers who wear their PPD reluctantly.
\end{abstract}

Keywords $\quad$ : Dust level, respiration complaint, Hobab Perkasa

\section{PENDAHULUAN \\ Latar Belakang}

Pembangunan sektor industri saat ini merupakan salah satu andalan dalam pembangunan nasional Indonesia. Tenaga kerja sebagai sumber daya manusia amatlah penting peranannya dari suatu kegiatan industri disamping modal dan peralatan. Oleh karena itu tenaga kerja harus dilindungi dari segala sumber bahaya. Bahaya pada lingkungan kerja dapat menimbulkan gangguan kesehatan tenaga kerja akibat dari pemaparan bahan baku maupun bahan buangan dalam proses produksi. Diantara berbagai gangguan kesehatan akibat lingkungan kerja, debu merupakan salah satu sumber gangguan yang tidak dapat diabaikan (Imaduddin, 2012).
Efek pemaparan debu terlihat pada tenaga kerja, yaitu kenikmatan kerja yang terganggu dan lama-lama bisa menimbulkan gangguan pada saluran pernafasan dan fungsi paru. Selain pengaruh pemaparan debu yang dapat menyebabkan keluhan pernafasan, ada beberapa faktor dari tenaga kerja, seperti: umur, masa kerja yang menggambarkan lamanya pemaparan debu, kebiasaan merokok dan kebiasaan memakai masker sebagai alat pelindung pernafasan mempengaruhi banyaknya penimbunan debu pada paru.

PT. Hobab Perkasa merupakan suatu perusahaan yang memproduksi plastik jenis PP dan Tali Rafia. Di dalam ruang produksi terutama pada gudang dan penyortiran bahan baku masih terlihat 
banyak debu. Sebagian besar tenaga kerja tidak menggunakan masker. Hal ini sangat berisiko karena tenaga kerja dapat terpapar oleh debu secara terus menerus yang bisa mengakibatkan suatu penyakit seperti gangguan pada saluran pernafasan.

\section{Tujuan Penelitian}

Mengetahui gambaran mengenai kadar debu dan keluhan pernafasan tenaga kerja pada bagian gudang dan penyortiran bahan baku produksi tali rafia di PT. Hobab Perkasa.

\section{METODE PENELITIAN}

\section{Jenis Penelitian}

Berdasarkan jenis penelitian dan analisa data termasuk penelitian deskriptif dengan pendekatan Cross Sectional.

\section{Lokasi dan Waktu Penelitian}

Penelitian ini dilaksanakan pada bagian gudang dan penyortiran bahan baku produksi tali rafia di PT. Hobab Perkasa yang beralamat di Karang Winongan KM 2 Mojoagung Kabupaten Jombang. Penelitian mulai dilakukan pada 28 April - 18 Mei 2013.

\section{hasil penelitian daN PEMBa- HASAN}

PT. Hobab Perkasa merupakan salah satu perusahaan yang memproduksi plastik jenis PP dan Tali Rafia. Bidang

\section{Populasi dan Sampel}

Populasi dalam penelitian ini yaitu seluruh tenaga kerja yang ada pada bagian gudang dan penyortiran bahan baku produksi tali rafia di PT. Hobab Perkasa. Besar sampel penelitian ini didapat dari jumlah tenaga kerja yang ada di bagian gudang dan penyortiran bahan baku produksi tali rafia PT. Hobab Perkasa dengan jumlah 30 orang.

\section{Variabel Penelitian \\ Variabel bebasnya adalah kadar debu yang terhirup oleh tenaga kerja. Dan yang menjadi variabel terikat adalah keluhan pernafasan yang dialami tenaga kerja.}

\section{Metode Analisis Data}

Data yang terkumpul selanjutnya diedit, dikompilasi dan disusun dalam bentuk tabel selanjutnya dianalisis secara deskriptif yaitu dengan menggunakan tabulasi silang yang menjelaskan obyek yang diteliti berdasarkan data-data yang diperoleh di lapangan dan hasil dari analisis tersebut digunakan untuk menarik kesimpulan.

usaha yang dilakukan PT. Hobab Perkasa adalah kegiatan daur ulang plastik. Hasil produksi PT. Hobab Perkasa adalah tali rafia plastik.

1. Pengukuran Kadar Debu di Tempat Kerja

TABEL 1

DISTRIBUSI FREKUENSI PENGUKURAN KADAR DEBU

DI DALAM GUDANG DAN TEMPAT PENYORTIRAN BAHAN BÁKU PT. HOBAB PERKASA

\begin{tabular}{|c|c|c|c|}
\hline No & Kadar Debu & Frekuensi & Prosentase (\%) \\
\hline 1. & Memenuhi syarat & 17 & 57 \\
\hline 2. & Tidak memenuhi syarat & 13 & 43 \\
\hline \multicolumn{2}{|c|}{ Total } & 30 & 100 \\
\hline
\end{tabular}

Dari hasil pengukuran kadar debu tersebut, diperoleh nilai hasil pengukuran sebanyak 17 sampel telah memenuhi syarat NAB, sedangkan sebanyak 13 sampel tidak memenuhi syarat NAB. Derajat kerusakan yang ditimbulkan oleh debu salah satunya dipengaruhi oleh jumlah debu yang masuk dan lama pemaparan. Hasil penelitian ini menunjukkan rata-rata hasil pengukuran kadar debu $0,16 \mathrm{mg} / \mathrm{m}^{3}$, dimana hasil tersebut melebihi NAB. Kadar debu yang tidak memenuhi syarat dipengaruhi oleh faktor lingkungan dan mekanisme kerja. Dalam hal ini faktor lingkungan yang mempengaruhi kadar debu tidak memenuhi syarat meliputi suhu yang tinggi dan kecepatan angin yang cukup besar. Untuk mekanisme kerja meliputi pemakaian 
masker yang tidak dilakukan oleh tenaga kerja, bahan baku yang sudah berdebu dan dibiarkan menumpuk sehingga jumlah debu semakin meningkat, serta mekanisme kerja karyawan dalam meletakkan atau mengambil barang juga dapat menyebabkan penyebaran debu yang lebih luas.

2. Keluhan Pernafasan Tenaga Kerja

TABEL 2

DISTRIBUSI TENAGA KERJA MENURUT TINGKAT KELUHAN PERNAFASAN DI GUDANG DAN PENYORTIRAN

BAHAN BAKU PT. HOBAB PERKASA TAHUN 2013

\begin{tabular}{|c|l|c|c|}
\hline No & \multicolumn{1}{|c|}{ Tingkat Keluhan } & Frekuensi & $\%$ \\
\hline 1. & Ringan & 2 & 7 \\
\hline 2. & Sedang & 18 & 60 \\
\hline 3. & Berat & 10 & 33 \\
\hline \multicolumn{2}{|c|}{ Total } & 30 & 100 \\
\hline
\end{tabular}

Berdasarkan tabel 2 dapat diketahui bahwa tingkat keluhan pernafasan dari 30 orang tenaga kerja, yang mengalami keluhan sedang 18 orang $(60 \%)$, yang mengalami keluhan ringan 2 orang $(7 \%)$ serta tidak ada responden yang menyatakan tidak mengalami keluhan apapun atau tanpa keluhan. Keluhan berat adalah adanya gangguan keluhan pernafasan yang dirasakan oleh tenaga kerja sampai mengalami sesak nafas. Keluhan sedang adalah adanya gangguan pernafasan yang dialami tenaga kerja sampai mengalami batuk, sedangkan keluhan ringan adalah keluhan yang dialami tenaga kerja meliputi bersin dan hidung tersumbat.

3. Distribusi Silang antara Karakteristik Tenaga Kerja dengan Keluhan Pernafasan

TABEL 3

DISTRIBUSI UMUR DENGAN KELUHAN PERNAFASAN TENAGA KERJA DI GUDANG DAN PENYORTIRAN BAHAN BAKU

PT. HOBAB PERKASA

\begin{tabular}{|c|c|c|c|c|c|c|c|c|}
\hline \multirow{2}{*}{$\begin{array}{c}\text { Umur } \\
\text { Responden }\end{array}$} & \multicolumn{6}{|c|}{ Keluhan Pernafasan } & \multicolumn{2}{c|}{ Jumlah } \\
\cline { 2 - 8 } & $\begin{array}{c}\text { Keluhan } \\
\text { Ringan }\end{array}$ & \multicolumn{2}{c|}{$\begin{array}{c}\text { Keluhan } \\
\text { Sedang }\end{array}$} & \multicolumn{2}{c|}{$\begin{array}{c}\text { Keluhan } \\
\text { Berat }\end{array}$} & \multicolumn{2}{c|}{} \\
\hline & $\mathrm{N}$ & $\%$ & $\mathrm{~N}$ & $\%$ & $\mathrm{n}$ & $\%$ & $\mathrm{n}$ & $\%$ \\
\hline$\leq 40$ tahun & 2 & 11 & 13 & 68 & 4 & 21 & 19 & 63 \\
\hline$>40$ tahun & 0 & 0 & 5 & 45 & 6 & 55 & 11 & 37 \\
\hline Jumlah & 2 & 7 & 18 & 60 & 10 & 33 & 30 & 100 \\
\hline
\end{tabular}

Berdasarkan tabel 3 dapat diketahui bahwa 30 orang tenaga kerja yang mengalami tingkat keluhan ringan yaitu 2 orang $(11 \%)$, untuk responden yang mengalami tingkat keluhan sedang yaitu 13 orang $(68 \%)$, dan responden yang mengalami tingkat keluhan berat sebanyak 4 orang $(21 \%)$. Debu yang masuk ke saluran pernafasan dapat mengakibatkan berbagai macam gangguan pernafasan. Seseorang yang berusia lebih dari 40 tahun biasanya fungsi jaringan elastisitas jaringan paruparunya berkurang sehingga kekuatan bernafas akan menurun dan dapat menimbulkan keluhan-keluhan pernafasan. Dalam penelitian ini menunjukkan bahwa kecenderungan tenaga kerja yang mengalami keluhan pernafasan lebih banyak pada umur $\leq 40$ tahun. Keluhan pernafasan juga bisa disebabkan karena kondisi cuaca yang buruk. Jadi dimungkinkan keluhan pernafasan yang dialami bukan disebabkan oleh umur namun kondisi cuaca yang buruk juga bisa menyebabkan keluhan pernafasan. 
TABEL 4

DISTRIBUSI MASA KERJA DENGAN KELUHAN PERNAFASAN TENAGA KERJA DI GUDANG DAN PENYORTIRAN BAHAN BAKU PT. HOBAB PERKASA

\begin{tabular}{|c|c|c|c|c|c|c|c|c|}
\hline \multirow{3}{*}{ Masa Kerja } & \multicolumn{6}{|c|}{ Keluhan Pernafasan } & \multirow{2}{*}{\multicolumn{2}{|c|}{ Jumlah }} \\
\hline & \multicolumn{2}{|c|}{ Keluhan Ringan } & \multicolumn{2}{|c|}{$\begin{array}{l}\text { Keluhan } \\
\text { Sedang }\end{array}$} & \multicolumn{2}{|c|}{$\begin{array}{c}\text { Keluhan } \\
\text { Berat }\end{array}$} & & \\
\hline & $n$ & $\%$ & $\mathrm{~N}$ & $\%$ & $\mathrm{~N}$ & $\%$ & $n$ & $\%$ \\
\hline$\leq 5$ tahun & 2 & 17 & 9 & 75 & 1 & 8 & 12 & 40 \\
\hline$>5$ tahun & 0 & 0 & 9 & 50 & 9 & 50 & 18 & 60 \\
\hline Jumlah & 2 & 7 & 18 & 60 & 10 & 33 & 30 & 100 \\
\hline
\end{tabular}

Berdasarkan tabel 4 dapat diketahui bahwa dari 30 orang tenaga kerja yang bekerja lebih dari 5 tahun mengalami tingkat keluhan sedang yaitu sebanyak 9 orang, serta responden yang mengalami tingkat keluhan berat sebanyak 9 orang. Dari penelitian tersebut menunjukkan adanya kecenderungan bahwa semakin lama masa kerja seseorang semakin besar pula pemaparan debu yang diterima. Menurut Muhammad Amin, salah satu faktor yang mempengaruhi derajat kerusakan organ pernafasan yang diakibatkan oleh debu yaitu lama pemaparan debu.

TABEL 5

DISTRIBUSI KEBIASAAN MEROKOK DENGAN KELUHAN PERNAFASAN TENAGA KERJA DI GUDANG DAN PENYORTIRANBAHAN BAKU

PT. HOBAB PERKASA

\begin{tabular}{|l|c|c|c|c|c|c|c|c|}
\hline \multirow{2}{*}{ Kebiasaan Merokok } & \multicolumn{6}{|c|}{ Keluhan Pernafasan } & \multicolumn{2}{c|}{ Jumlah } \\
\cline { 2 - 9 } & \multicolumn{2}{|c|}{ Keluhan Ringan } & \multicolumn{2}{c|}{$\begin{array}{c}\text { Keluhan } \\
\text { Sedang }\end{array}$} & \multicolumn{2}{c|}{ Keluhan Berat } & \multicolumn{2}{c|}{} \\
\cline { 2 - 10 } & $\mathrm{n}$ & $\%$ & $\mathrm{~N}$ & $\%$ & $\mathrm{n}$ & $\%$ & $\mathrm{n}$ & $\%$ \\
\hline Merokok & 0 & 0 & 12 & 63 & 7 & 37 & 19 & 63 \\
\hline Tidak Merokok & 2 & 18 & 6 & 55 & 3 & 27 & 11 & 37 \\
\hline Jumlah & 2 & 7 & 18 & 60 & 10 & 33 & 30 & 100 \\
\hline
\end{tabular}

Berdasarkan tabel 5 dapat diketahui bahwa tenaga kerja yang memiliki kebiasaan merokok dan mengalami keluhan sedang yaitu sebanyak 12 orang, sedangkan yang mengalami keluhan berat sebanyak 7 orang. Asap rokok dapat memperlambat gerakan cilia dan setelah jangka waktu tertentu akan menyebabkan gerak cilia menjadi lumpuh. Seseorang yang mempunyai kebiasaan merokok akan lebih mudah menderita radang paru. Hal ini sejalan dengan hasil penelitian bahwa jumlah tenaga kerja yang merokok dan mengalami keluhan pernafasan lebih besar dari tenaga kerja yang tidak merokok.

TABEL 6

DISTRIBUSI KEBIASAAN MENGGUNAKAN MASKER DENGAN KELUHAN PERNAFASAN TENAGA KERJA DI GUDANG DAN PENYORTIRAN BAHAN BAKU

PT. HOBAB PERKASA

\begin{tabular}{|c|c|c|c|c|c|c|c|c|}
\hline \multirow{2}{*}{$\begin{array}{c}\text { Kebiasaan } \\
\text { Memakai Masker }\end{array}$} & \multicolumn{6}{|c|}{ Keluhan Pernafasan } & \multicolumn{2}{|c|}{ Jumlah } \\
\cline { 2 - 9 } & \multicolumn{2}{|c|}{ Keluhan Ringan } & \multicolumn{2}{c|}{$\begin{array}{c}\text { Keluhan } \\
\text { Sedang }\end{array}$} & \multicolumn{2}{c|}{$\begin{array}{c}\text { Keluhan } \\
\text { Berat }\end{array}$} & \multicolumn{2}{c|}{} \\
\cline { 2 - 9 } & $\mathrm{N}$ & $\%$ & $\mathrm{n}$ & $\%$ & $\mathrm{~N}$ & $\%$ & $\mathrm{n}$ & $\%$ \\
\hline Ya & 2 & 100 & 0 & 0 & 0 & 0 & 2 & 7 \\
\hline Tidak & 0 & 0 & 18 & 64 & 10 & 36 & 28 & 93 \\
\hline Jumlah & 2 & 7 & 18 & 60 & 10 & 33 & 30 & 100 \\
\hline
\end{tabular}


Berdasarkan tabel 6 dapat diketahui bahwa tenaga kerja yang tidak menggunakan masker dan mengalami keluhan sedang yaitu sebanyak 18 orang dan untuk tenaga kerja yang mengalami keluhan berat yaitu sebanyak 10 orang. Hal ini menunjukkan bahwa kecenderungan memakai masker dapat mengurangi pemajanan terhadap debu sehingga dapat mengurangi keluhan pernafasan.

TABEL 7

DISTRIBUSI HASIL PENGUKURAN KADAR DEBU DENGAN KELUHAN PERNAFASAN TENAGA KERJA DI GUDANG DAN PERYORTIRAN BAHAN BAKU

PT. HOBAB PERKASA

\begin{tabular}{|c|c|c|c|c|c|c|c|c|}
\hline \multirow{2}{*}{ Kadar Debu } & \multicolumn{6}{|c|}{ Keluhan Pernafasan } & \multicolumn{2}{c|}{ Jumlah } \\
\cline { 2 - 10 } & $\begin{array}{c}\text { Keluhan } \\
\text { Ringan }\end{array}$ & $\begin{array}{c}\text { Keluhan } \\
\text { Sedang }\end{array}$ & \multicolumn{2}{c|}{$\begin{array}{c}\text { Keluhan } \\
\text { Berat }\end{array}$} & \multicolumn{3}{|c|}{} \\
\cline { 2 - 10 } & $\mathrm{N}$ & $\%$ & $\mathrm{~N}$ & $\%$ & $\mathrm{n}$ & $\%$ & $\mathrm{n}$ & $\%$ \\
\hline Memenuhi Syarat & 2 & 12 & 14 & 82 & 1 & 6 & 17 & 57 \\
\hline Tidak Memenuhi Syarat & 0 & 0 & 4 & 31 & 9 & 69 & 13 & 43 \\
\hline Jumlah & 2 & 7 & 18 & 60 & 10 & 33 & 30 & 100 \\
\hline
\end{tabular}

Berdasarkan tabel 7 dapat diketahui bahwa tenaga kerja yang mengalami keluhan pernafasan dengan kadar debu yang memenuhi syarat NAB dengan kategori keluhan ringan sebanyak 2 orang dengan prosentase sebesar $12 \%$, untuk tenaga kerja yang mengalami keluhan sedang sebanyak 14 orang dengan prosentase sebesar $82 \%$ dan untuk tenaga kerja yang mengalami keluhan berat ada 1 orang dengan prosentase $6 \%$. Faktor yang menentukan besarnya gangguan kesehatan akibat debu, salah satunya adalah kadar debu di udara. Makin tinggi kadar debu, makin cepat menimbulkan gangguan kesehatan dan kenikmatan dalam bekerja. Hal ini menunjukkan bahwa debu berpengaruh terhadap timbulnya keluhan pernafasan, kadar debu yang rendah bukan berarti tidak menimbulkan keluhan pernafasan karena apabila debu terhirup oleh tenaga kerja secara terus menerus dan dalam jangka waktu yang lama, maka tenaga kerja akan mengalami keluhan pernafasan.

\section{KESIMPULAN}

1. Pengaruh umur dengan keluhan pernafasan

Kecenderungan tenaga kerja yang mengalami keluhan pernafasan lebih banyak pada umur $\leq 40$ tahun.

2. Pengaruh masa kerja dengan keluhan pernafasan

Keluhan pernafasan terbanyak dialami oleh tenaga kerja yang memiliki masa kerja lebih dari 5 tahun. Adanya kecenderungan bahwa masa kerja mempengaruhi keluhan pernafasan.

3. Pengaruh kebiasaan merokok dengan keluhan pernafasan

Keluhan pernafasan terbanyak dialami oleh tenaga kerja yang memiliki kebiasaan merokok. Adanya kecenderungan bahwa kebiasaan merokok mempengaruhi keluhan pernafasan tenaga kerja.

4. Pengaruh penggunaan APD (masker) dengan keluhan pernafasan

Keluhan pernafasan terbanyak dialami oleh tenaga kerja yang tidak menggunakan masker selama bekerja. Adanya kecenderungan memakai masker dapat mempengaruhi keluhan pernafasan.

5. Pengaruh kadar debu dengan keluhan pernafasan

Keluhan pernafasan terbanyak terlihat pada pengukuran kadar debu yang masih memenuhi syarat.

\section{SARAN}

1. Dari hasil pengukuran kadar debu yang cukup tinggi maka sebaiknya pihak perusahaan memasang Local Exhaust Ventilation untuk mengurangi kadar debu di bagian mesin pemeletan.

2. Sebaiknya perusahaan bekerjasama dengan instansi terkait untuk melakukan pelatihan tentang K3 secara berkala kepada tenaga kerjanya, atau penyuluhan tentang K3 khususnya tentang paparan debu terhadap tenaga 
kerja, cara kerja yang aman, manfaat pemakaian APD, dan pemeliharaan hygiene perorangan yang baik serta sadar akan budaya selamat (safety behavior) dalam setiap melakukan pekerjaan.

3. Sebaiknya perusahaan memberikan sanksi yang tegas bagi tenaga kerja yang tidak menggunakan APD.

4. Sebaiknya pihak perusahaan menyediakan kamar ganti karyawan

\section{DAFTAR PUSTAKA}

Amin, Muhammad, 1996. Penyakit Paru Obstruktif Menahun. Surabaya, Airlangga University Press: $54-76$.

Fardiaz, Srikandi, 1992. Polusi Air dan Udara. Yogyakarta, Kanisius. 138.

Harrianto, Ridwan, 2010. Buku Ajar Kesehatan Kerja. Jakarta, Buku Kedokteran EGC. 30 - 35, 87, 109.

Keputusan Menteri Kesehatan Republik Indonesia, 2002. Tentang Persyaratan Kesehatan Lingkukngan Kerja dan Industri. Nomor 1405/MENKES/SK/2002.

Moeljosoedarmo, Soeripto, 2008. Higiene Industri. Jakarta, Fakultas Kedokteran Universitas Indonesia: 51.

Mukono, H.J, 1997. Pencemaran Udara dan Pengaruhnya terhadap Gangguan Saluran Pernapasan. Surabaya, Airlangga University Press. 23. yang dilengkapi dengan loker karyawan serta menjaga kondisi kamar mandi agar selalu bersih dengan cara memperkerjakan petugas khusus untuk membersihkan lingkungan perusahaan.

5. Dari hasil penelitian ini diharapkan dapat dilakukan penelitian lebih lanjut tentang kadar gas maupun kontaminan lainnya yang dihasilkan dari proses produksi.

Pudjiastuti, Wiwiek, 2002. Debu Sebagai Bahan Pencemar yang Membahayakan Kesehatan Kerja. Pusat Kesehatan Kerja Departemen Kesehatan RI.

Siswanto, A, 1991. Ventilasi Industri. Balai Hiperkes dan Keselamatan Kerja Jawa Timur: $2-70$.

Suma'mur P.K, 1988. Higiene Perusahaan dan Kesehatan Kerja. Jakarta, CV Haji Masagung: $105-106$.

Suma'mur P.K, 2009. Higiene Perusahaan dan Kesehatan Kerja. Jakarta, Sagung Seto: 238 - 283.

Yusnabeti, dkk, 2010. PM 10 dan Infeksi Saluran Pernapasan Akut Pada Pekerja Industri Mebel. Makara Kesehatan, Juni 2010 (14): 25-30. 